\title{
Prof. Dr. Necmettin Hacıeminoğlu Hatıra Kitabı, Türk Edebiyatı Vakfı Yayınları, İstanbul 2017, 759 s.
}

\begin{abstract}
Ali YÖRÜR*
Toprakta gezen gölgeme toprak çekilince

Günler şu heyûlâyı da er geç silecektir

Rahmetle anllmak ebediyet budur ammâ

Sessiz yaşadım kim beni nerden bilecektir
\end{abstract}

Mehmet Akif Ersoy

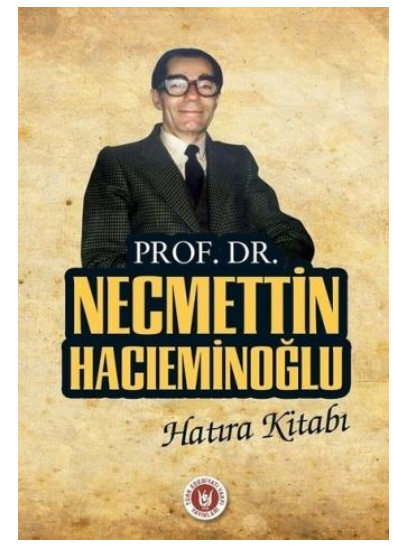

İnsanlık âleminde tarihten günümüze kadar eğitim, ilim, irfan sahasında birçok münevver kişiler gelip geçmiştir ki onlar bütün ömrünü kendi vatanı, milleti ve insanlık âleminin yararı için bağışlayıp evlattan evlada anılacak derin izler bıraktılar. Prof. Dr. Necmettin Hacıeminoğlu da bu şahsiyetlerin içinde yer alan münevverlerden biridir.

Türkoloji ilmine büyük katkıları olan Prof. Dr. Necmettin Hacıeminoğlu 26.06.1996 tarihinde hayata gözlerini yummuştur.

Hocanın vefatının yirminci yılında mesai arkadaşları, öğrencileri ve üniversitelerin Türk Dili ve Edebiyatı bölümlerindeki hocaların çalışmalarının yer aldığı bir hatıra kitabı hazırlanmıştır. Prof. Dr. Ali İhsan Öbek, Doç. Dr. Yüksel Topaloğlu ve Doç. Dr. Oğuzhan Durmuş'un

\footnotetext{
* Doktora öğrencisi, Trakya Üniversitesi Sosyal Bilimler Enstitüsü Türk Dili ve Edebiyatı Anabilim Dalı Türk Edebiyatı Bilim Dalı. ali.yorur@hotmail.com, ORCID: htps://orcid.org/0000-0003-1434-2995
} 
editörlüğünde hazırlanan kitap, Türk Edebiyatı Vakfı Yayınları tarafından 2017'de yayınlanmıştır.

Kitabın giriş bölümünde Trakya Üniversitesi Türk dili ve edebiyatı bölümü başkanı Ali İhsan Öbek'in sunuş yazısı ve Yüksel Topaloğlu'nun Prof. Dr. Necmettin Hacieminoğlu'nun hayatı, ilmî, edebî şahsiyeti ve eserlerini kaleme aldığı yazısı bulunmaktadır.

“Albüm ve Hatıra Yazıları" başlı̆̆ı altında Birol Emil'in Prof. Dr. Necmettin Hacıeminoğlu, Recep Duymaz'ın Bir Ülkü Adamından Hatıralar, Sultan Mahmut Kaşgarlı'nın Üstat Prof. Dr. Necmettin Hacteminoğlu'nu Saygı ve Sevgiyle Anıyoruz, Hasan Çebi'nin Emin Adam, Esat Can'ın Hocam Prof. Dr. Necmettin Hacıeminoğlu, Cevdet Şanlı'nın Necmettin Hocamla Altı Yll, Özcan Aygün'ün Prof. Dr. Necmettin Hacieminoğlu ile Sirpsindiğ Anıtını Ziyaret, Osman Fikri Sertkaya'nın Necmettin Hacıeminoğlu ve Türkolojiden Hatıralar, Dursun Yıldırım'ın Necmettin A ğabey ile Üniversite Günlerinden, Ali Çavuşoğlu'nun Necmettin A ̆gabey ve Muharrem Dayanç'ın Taşradan Gelen Bir Öğrenci Gözüyle Necmettin Hacıeminoğlu isimli hatıra yazıları bulunmaktadır.

Daha sonra "Makaleler" bölümü bulunmaktadır. Makaleler, dil ve edebiyat olmak üzere iki başlık altında toplanmıştır. Dil başlığı altındaki makaleler; Eski Türk Dili, Yeni Türk Dili, Çağdaş Türk Lehçeleri, Anadolu ve Rumeli Ağızları alanındaki makalelerden oluşmaktadır. Edebiyat başlığı altındaki makaleler; Eski Türk Edebiyat1, Yeni Türk Edebiyatı ve Halk Edebiyatı alanındaki makalelerden oluşmaktadır.

Eski Türk Dili alanında Mustafa Argunşah'ın Codex Cumanicus'ta Arapçadan Alıntı Kelimeler Üzerine Notlar (I), Ahmet Bican Ercilasun'un Dîvânu Lugâti't-Türk Hakkında, Osman Fikri Sertkaya'nın Hasan Ebû Kara Sâ'il Şemsî'nin 1436 Yılında Herat'ta Uygur Harfleriyle Yazdiğı Kaside, Nursel Dinler'in Eskicil Bir Hastalık Adından Argoya: Gıcık, Sinan Güzel'in Edal'ın Ana Bulgarca Tburemb Biçimine İlişkin Tespitlerine Çuvaşça Temelinde Bir Düzeltme, Hülya Uzuntaş'ın İslamî Devrede Yazılan Uygur Harfli Çağatayca Seyfe'l-Mülûk ve Bedî’ü'l-Cemâl Hikâyesi ve Gramer Analizi ve Denis Sinor (Çev. Nilay Altunay)'in Eski Türkçedeki Samoyedce ve Ugorca Unsurlar isimli makaleleri bulunmaktadır.

Yeni Türk Dili alanında Hülya Arslan Erol'un “mAzIyA” Zarf-Fiili Üzerine, Rıdvan Canım'ın Ĕgitim-Öğretim Hayatımız İçinde Türkçenin Yeri veya Türkçe Nereye Gidiyor?, Vahit Türk'ün Türkçede İnanmak Fiili ve Ailesi, Saadettin Yıldız'ın Edebî Metinlerde Zenginleşen Türkçe, Beytullah 
Bekar'ın Almanya'nın Türkçeye Yönelik Dil Planlama Çalışmaları ve Sonuçlarl, E. Serap Bozkurt'un Oğuz Atay - Tehlikeli Oyunlar ve Haydar Ergülen - Üzgün Kediler Gazeli Eserlerinde Yer Alan Zamirlerin Özne Konumundaki Anlam Yükleri, Selda Sandalyeci'nin Necmettin Hacteminoğlu'nun Makalelerinde ve Hikayelerinde Görülen Üslup Özelliklerinin Cümle Düzeyinde Karşılaştırılması ve Melike Somuncu'nun Behcetü'l-Hadâ'ik Eserinin Berlin Nüshası isimli makaleleri bulunmaktadır.

Çağdaş Türk Lehçeleri alanında Ercan Alkaya'nın Türk Lehçebilim Araştırmaları İçinde Sibirya Tatar Türkçesinin Yeri ve Durumu Üzerine, Sema Aslan Demir'in Türkmencede er- Ek Fiilinin Yan Cümledeki Sözdizimsel ve Görünüş-Zamansal İslevleri, Salih Demirbilek'in -Rdal (X)Rda Zarf-Fiil Ekinin Tarihi ve Çağdaş Türk Lehçelerinde Kullanım Biçimleri, İlker Tosun'un Tuva Türkçesinde "Ol” Enklitiği ve Lavrence Krader (Çev. Sevgi Öztürk)'in Kazak Etnomimi isimli makaleleri bulunmaktadır.

Anadolu ve Rumeli Ağızları alanında Ahmet Günşen'in Batı Rumeli Türk Ağızlarında Kullanılan Farklı Bir Şahıs Eki: -sık, sUK, Leylâ Karahan'ın A ğızların Korunmasında Cinsiyetin Rolü Üzerine Bir Araştırma: Kütahya, Erzurum ve Trabzon Ağızları Örneği, Fatma Sibel Bayraktar'ın Anadolu A ğızlarında Devrik Cümle ve Zarf ve Levent Doğan'ın Kırklareli Ağzında İkilemeler isimli makaleleri bulunmaktadır.

Eski Türk Edebiyatı alanında Ömür Ceylan - Ozan Yılmaz'ın Klasik Türk Siiri'nde Ermenilere Dair, Ali İhsan Öbek'in Varak-ı Mihr ü Vefâ,, Gülçiçek Akçay'ın Divan Şiiri Penceresinden Âşı̆̆ın Bilinçaltını Temâşâ: Düş’te Yâri Tenhâ Düş'ürmek, Kaşif Yılmaz'ın III. Selim'in (İlhâmî) Divanı ve Edebî Yönü ve Halil Karabulut'un Tahir Olgun'un Yavuz Mersiyesi Şerhi isimli makaleleri bulunmaktadır.

Yeni Türk Edebiyat1 alanında Hülya Argunşah'ın Tanzimat'tan Cumhuriyet'e Bir Sosyal Veri Kaynă̆ Olarak Kadın Yazarlar ve Eserleri, Bilge Ercilasun'un Tarihî Romanın Anlamı ve Üç Kitap, Abdullah Uçman'ın Türkçede Terimler Meselesi ve Istılahât-ı Illmiyye Encümeni, Mehmet Güneş'in Rumeli'ye Elveda Derken: Bulgaristan Türklerinin Trajedisinin Galip Sertel'in Şiirlerindeki Yansımalart, Yüksel Topaloğlu'nun Akif ve Fikret Davasina 'Nazifane' Bir Baklş, Özcan Aygün'ün Edirne’ye Edeb̂̂ Açıdan Bir Bakış Denemesi, Esat Can'ın Romancıların Gözüyle Mustafa Kemal, İsa Kocakaplan'ın Mehmet Akif'te Balkan Acısl, Barış Berhem Acar'ın Nesneleşen Özneler: Kurtuluş Savaşı'nı Konu Alan Metinlerde Çocukluğun İnşası, Seda Çetin'in Sembolleştirilen Bir Mücadele: Ateşten 
ALİ YÖRÜR

Gömlek Romanını İmge ve Sembolleri Üzerinden Okumak ve Ayșe Nur Özdemir'in Ahmet Mithat Efendi'nin Romanlarında Çok Eşlilik Meselesi isimli makaleleri bulunmaktadır.

Halk Edebiyatı alanında Mehmet Aça'nın Şu Destanı'ndaki “Öge”den Reşideddin Oğuznamesi’ndeki Yuşi Hocaya, Özkul Çobanoğlu'nun Aydın ve Halk Kaynaşması Bağlamında Sivas Halk Şairleri Bayramı, Bülent Bayram'1n Türkiye'de Çuvaş Folklar Araştırmaları Örneğinde Mitoloji Araştırmalarında Kaynak ve Metin Sorunları Üzerine, Oğuzhan Durmuş'un Türkiye Türkçesinin Basll Illk Atasözleri: H. Megiser'in Paroemiologia Polyglottos Adlı Eserinde Yer Alan Atasözleri, Ömer Aksoy'un Boşnak Halkının Ortak Belleği Bağlamında Mostar Köprüsü, Emin Kalay'ın Edirne İli Halk Kültüründeki Atasözü ve Deyimler, Erhan Aktaş'ın Hakas Atasözleri-I ve Cemalettin Yavuz'un Çuvaş Efsanelerinde Kozmogonik Bir

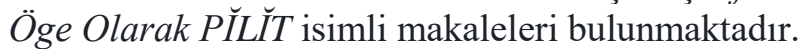

Kitabın son bölümünde "Tarih-Kültür-Sanat" başlığı bulunmaktadır. Bu bölümde, Engin Beksaç - Şule Nurengin Beksaç'ın Edirne ve Kırklareli'de Bulunan Trak Kaya Sunakları ve Bağıntılı Kült Anıtları, Mustafa Volkan Coşkun - Didem Çetin - Perihan Gülce Özkaya'nın MSKÜ Ĕ̆itim Fakültesi Türkçe Ĕ̌itimi Bölümü Öğrencilerinin Değer Algllarl, Nevzat Özkan'ın Kayseri'deki Uygur Türkleri Diasporası, Suphi Saatçi'nin Yazma Kaynaklara Göre Mimar Sinan Yapıları ve Cevdet Şanlı - Jergin Jable'nin Balkanlarda Türk'e Barikatlar isimli yazıları bulunmaktadır.

Vefalı öğrencilerinin rahmetli Necmettin Hacıeminoğlu Hoca'y1 güzel bir hatıra kitabıyla andığı bu kıymetli eserin oluşumunda başta Prof. Dr. Ali İhsan Öbek, Doç. Dr. Yüksel Topaloğlu, Doç. Dr. Oğuzhan Durmuş ile Türk Edebiyatı Vakfı yetkilileri olmak üzere emeği geçen herkese teşekkür ederiz. 